\title{
Ruminations on Time
}

(2005-2009)

\section{LUCY TATMAN}

UNIVERSITY OF TASMANIA

The apocalypse did not occur on schedule. Mind you, since the apocalypse has never occurred as predicted, this is not new. What is new is that this time, for the first time, every single inhabitant of Western culture had been primed, as it were, to expect-something. Even the most resolute atheists had Y2K, for God's sake. Yet we received nothing. Unless you happened to have been in Budapest, Hungary, on the night of 31 December 1999. When/where, if you were on the Pest side of the Danube, in between the Margit Island and Széchenyi Chain bridges, you received a veritable pea soup of a fog. While there were bodies in abundance, bodies jam packed together, it was impossible to see beyond your nearest neighbour's shoulder. 'Thump', we heard, quietly. And then there was perhaps a vaguely coloured patch up and over the river. After a moment the invisible crowd realised that was It, the fireworks had begun. Thump. Thump thump. That was it. The crowd dispersed. Slowly. Quietly. But the post-non-apocalypse fog remains, I think. And if such a fog could take the form of a question, that question might well be, 'When are we now?' When, indeed. 
'Welcome to the Digital Age.' I read it on a t-shirt, so it must be true. This is the digital age. A spatio-temporal modality whose landscape is the netscape, where information flows 24/7, flashes of light pulsing on and off, on and off over a million times per second as they race down optical fibre cables at speeds no human can achieve. Indeed, no human can even bear witness to these binary messengers. To our naked eyes those pulses of light appear as an unbroken stream. But all those packets of information, lightly encoded, are in fact all scrambled, all a'jumble. In transit they get divided, split apart, each little packet like a postcard on which is written one or two words of the entire missive. Each little packet routed and rerouted willy-nilly down the fastest available track until, at last, so soon, arriving at their destination they are all arranged once more in their proper order. The digital Humpty-Dumpty is put back together again 24/7.

But human beings, while jumbled creatures, are not non-stop 24/7 entities in quite the same way as information. We require sleep, and showers, and touches, and the occasional silly conversation, and the odd moment spent hanging out the laundry or getting that tattoo and the dog really needs to be walked and when are you going to fix that dripping tap? But all the while the Digital Age is digiting away, the Information Era is informationing, and there's so much to take in and we cannot, any one of us, possibly keep up. Blink, and you've fallen behind. Dare to take a nap and you awake hopelessly out of date.

In Proust and the Sense of Time, Julia Kristeva wrote that 'we live in a dislocated chronology, and there is as yet no concept that will make sense of this modern, dislocated experience of temporality. ${ }^{1}$ Dislocated. Out of joint, out of place. In the far hamlets of northern Alabama/southern Tennessee there is an expression which is used to indicate a situation in which you are not in the place where you are expected to be, the place where you fit, belong. 'Out of pocket.' I know of no temporal equivalent to this precisely spatial expression, but if there were I'd say we are all perhaps feeling somewhat out of pocket. It is the Digital Age, yet our own digits are slow-moving and subject to arthritis. We require lengthy periods of time in which to sort through, absorb and 'digest' information, to transform it into knowledge. ${ }^{2}$ By the time we have done so, we are always already behind the times, out of it. 
Distemporalated, I would suggest. Which could be translated as temporally unhinged, slowly adrift somewhen not of the digital present.

It is a tense predicament. ${ }^{3}$ When, later tonight or tomorrow, I opened my laptop computer, I then will have seen, again, black plastic framing a liquid crystal display screen. Did I subject myself to viewing 'the latest' international news? Would I have noticed that the alarming headline is duly followed by the equally alarming news that it was posted $3 \mathrm{hrs} 18$ mins ago? Might the realisation well up within me-I seem to be making incarnate a new verb tense, the present anterior. A nowly belated observer of a just past present.

Black plastic framing a liquid crystal display screen. The digital age. Gazing at that screen, all I see are traces, remnants of a moment that flew past, that has always already passed by. This morning the laptop sits on the floor beside the armchair. I am pondering its plastic frame. Made from petroleum products. I am thinking about those ancient leafy greens which, in their time, unfolded in the sun, were touched by wind and rain, eventually died, decayed, rotted completely away, were covered over and over and over and over and the pressure slowly grew, and the heat increased, and millions of years later a forty-three year old woman wearing a bathrobe with deep pockets looked in astonishment at the thing on her floor, that thing which so unsubtly serves to technologically enframe a temporal modality within which human beings cannot dwell-more precisely, a temporal modality which cannot include human beings in its present. In relation to digital time we human creatures always lag behind. What is revealed in the frame of those ancient leafy greens is the impossibility of human coming to digital presence. ${ }^{4}$

In her 1979 essay 'Women's Time', Julia Kristeva wrote of three temporal modalities: time cyclical, monumental and linear. Cyclical time she characterised as the time of 'repetition'; monumental time she described as the time of 'eternity', while linear time was the time of 'development'. 5 The first two temporal modalities, she noted, were gendered feminine, the latter masculine. Three temporal modalities, all of them co-existing, although access to the cyclical and monumental was, for the masculine subject, available almost exclusively through mystical or quantum physical channels, while access to the linear was, for the feminine subject, difficult. 
That all three temporal modalities existed Kristeva was able to take for granted in 1979.

Re-reading her essay in 2007, what struck me forcibly is that linear time is not a temporal modality I am able to take for granted-and not because I am not a masculine subject. Rather, simply, shockingly, it no longer exists. To be clear, time still exists-that inexorable passing as experienced and measured by humans, the sort of time in which things happen, this perdures. It is that particular temporal modality known as linear time that is no longer. That is, there is no longer a time of linear progress, of positive development, a time of social, national and international improvement into which any subjects could attempt to gain entry. The shiny happy always-getting-better future promised by linear time simply is no more. In its place we are now assured of rising sea levels, extreme flooding and catastrophic droughts. We are informed of rapidly increasing rates of species' extinctions. We are promised leaking containers of nuclear waste instead of reliable energy too cheap to meter. We can look forward to famine, starvation, epidemics and mass human migrations, which will lead in turn to regional armed conflicts over scarce resources like water, kindness, grain, compassion, vegetables, and so on. ${ }^{6}$ I am reminded of these words from Adrienne Rich: 'I don't want to know | wreckage, dreck and waste, but these are the materials.' 7 Materially, the time of linear progress is over. Tellingly, I know of no one who imagines that things will only get better.

I find it almost impossible to write about the non-existence of progressive linear time, perhaps because it is inconceivable that this temporal modality-along side which I was born, within which I was educated, about which the covers of popular magazines continually assured me-has disappeared. Perhaps it is difficult to write about the disappearance of linear time simply because it is so closely akin to the emperor's new clothes. It was, after all, a very masculine, virile time. Surely linear time was the proud motherless son of Francis Bacon, a son who did indeed grow big and strong. But the time of Bacon's 'masculine birth' has come to a halt. The son no longer tells the time.

One of the primary pieces of evidence for the death of this masculine, filial, linear temporality is the current attraction on the part of so many to paternal time. 
To a religious temporality that begins and ends with the Father. Unfortunately, it is almost as difficult to write about the living existence of this paternal temporal modality as it is to write about the recent death of linear time. Paternal religious time was supposed to have died already. Such was the testimony and the verdict and also the guilty Oedipal fantasy of secular, linear, filial time. Such was also the hope and affirmation of a great many feminist thinkers, many of whom were working for the right of female access to linear time.

It's complicated. Kristeva was writing specifically, narrowly/broadly, about Europe, about a distinctive European obsession with developing and transporting/ extending/imposing its civilisation upon others. She fully recognised, I think, that this temporal modality enslaved most tightly the minds of those who believed they were its masters. Equally important to recognise is the fact that all subjects everywhere who encountered this obsessive time were sentenced and imprisoned by it to some bodily degree. Indeed, it required for its continual linear extension bodies in abundance. The maternal body-space of origin, the virginal body-space of arrival, and the muscled body-space of labourers - the bodies building the roads, the ships, laying the rails, shovelling the coal, mining the metals required for departure, transport and arrival. My point? There were lots and lots of unacknowledged bodies required and imprisoned by linear time.

Now that the time of linear progress has passed, are those bodies free at last? Are they now acknowledged? Has there emerged a temporal modality in which they are included, welcomed? Search as I might, I have been able to find only a yelp of horror at the sudden appearance of all those bodies. In 2003 Fredric Jameson published 'The End of Temporality', an essay in which he defined that 'end' as 'the reduction to the present and to the body'. ${ }^{8}$ I'll let him explain how 'the multiplicity of other people' brought an end to both past and future, for I couldn't begin to do justice to his thought: 9

the movement of decolonisation that followed [the world wars] ... suddenly released an explosion of otherness unparalleled in human history ... It is this explosive fact of decolonisation that now ... confronts me with an immense multitude of others, which I am called upon to 
recognize as equals or as freedoms. But in our present context the point to be made has to do with the impact of this recognition on the experience of the bourgeois self, for it is the proliferation of all these innumerable others that renders vain and inconsequential my own experience of some essence I might be, some unique life or destiny that I might claim as a privilege (or indeed as a form of spiritual or existential private property). The stripping away of that form of temporality - the security of the ego or the unique personal self - ... leaves me alone with my unique present, with a present of time that is anonymous and no longer belongs to any identifiable biographical self or private destiny. ${ }^{10}$

'Time that is anonymous and no longer belongs to any...'? At the very least it would seem that the masculine subject is no longer having the time of his life. Go figure.

'Figuration', according to Donna Haraway, 'is the mode of theory when the more "normal" rhetorics of systematic critical analysis seem only to repeat and sustain our entrapment in the stories of the established disorders.'11 More bluntly, Rosi Braidotti proposes 'figurations as a way out of the old schemes of thought', stressing 'the potency and relevance of the imagination, of myth-making, as a way to step out of the political and intellectual stasis of these postmodern times'.12 Crucially, Braidotti defines postmodernity as the current historical moment, simply the time in which we now dwell. That these are telling times is a matter of concern to both Braidotti and Haraway. What concerns me is how we are telling these times, how we are and are not able to figure them.

Mountain, myth, calendar, watch. Mountain, myth, calendar, watch. The words move through my mind like a mantra. Each one the material form of a different temporal modality. The list, I know, is woefully incomplete. And this is what astonishes me: the extraordinary capacity human beings demonstrate for making multiple temporal modalities incarnate, or for imagining and materialising and telling and living, constantly, numerous temporalities. Mountain, myth, calendar, watch. We go to exceptional lengths to make time matter. 
I suspect that it is not a coincidence that I am doing this thinking here, in the shadow of Kunanyi, that monumental temporal form known to more recent immigrants as Mt Wellington. Weightily present at a distance, Kunanyi is simultaneously a geographical and a temporal point of reference for all inhabitants of Hobart. It is the massive, monumental presence in relation to which we orient ourselves, both placially and temporally. But what is the temporality of such a monumental place? Bart Verschaffel suggests 'that the "content" of the monumental form is the visualisation of a relation between time and stone'. ${ }^{13}$ How gorgeously evocative, but so abstract. Perhaps this will help.

The time frame of [Hindu] cosmology boggles the [Western] imagination ...

The Himalayas, it is said, are made of solid granite. Once every thousand years a bird flies over them with a silk scarf in its beak, brushing their peaks with its scarf. When by this process the Himalayas have been worn away, one day of a cosmic cycle will have elapsed.14

What a relation between time and stone. So much temporal 'distance' sedimented into one relate-to-able place. But Huston Smith is right. This is not the way that cosmological time is imagined, materialised and told in Western culture. For twentyfirst-century Westerners, cosmological time is made incarnate by the expansive relations between galaxies and galaxy clusters, between black holes and dark energy. It is a vast rushing, spiralling, racing time in relation to which the entire existence of that entity known as humankind-from go to woe-is not even a fingernail clipping. Cosmological time is a temporal modality whose dimensions are of such a magnitude that we cannot begin to conceive it, it is unvisualisable. For this reason, it is a wholly different temporal modality to monumental time. As Verschaffel reminds us, 'The monumental ... even when it surpasses ordinary bodies in size, is defined and measured by the scale of the body.'15 I would suggest that it is only as particles, or as recyclable dashes of energy and elementary bits of atoms that we (Western) human subjects relate to cosmological time. We know, that is, that we are inextricably a part of it-but it is as if, in our human form, we are rather extricated from it-extricated, and at such a distance to it. It doesn't seem to need us as human subjects to help make its temporality incarnate. It only needs the particles of which we are composed. How different to the way we imagine and relate to monumental time. From the perspective of our human lives, there is a most 
enduring quality to monumental time. While not entirely unchanging, it is nonetheless a solid temporality, 'without cleavage or escape', in Julia Kristeva's words. ${ }^{16}$

When describing the massive, passive presence of monumental time, Kristeva noted the Christian belief in the assumption and/or dormition of Marythe mother of God who simply/not so simply did not die: she who endures. My imagination leans in a more concrete direction. I think of Lot's wife. Of the woman who insisted on bearing witness to the annihilation of the only home she had ever known. Its name was Sodom, and for her effort she was turned into a pillar of salt. Could it have been the sedimentation of all the tears she shed while watching such destruction? It wasn't the Sodomites' fault that an upstart foreign God didn't like their customs.

Monumental time does not seem to discriminate on the basis of religion, nationality, or custom. It bears witness to everything within sight. It honours the insignificant just as much as the significant. It bears witness to what is. Monumental time transcends nothing. It cannot stop the passage of other times, but it endures those passages. It bears traces of them long after they have gone. It remembers, or at least we human beings imagine that monumental time remembers-and remembers not only monstrous or cataclysmic events which we would rather not think about on a daily basis, but also our own fleeting lives. As insignificant/significant as the brush of a silk scarf across a mountain peak. Each one of us, remembered by monumental time. There is something deeply comforting about this temporality, rather like a maternal embrace. But, rather like a maternal embrace, there is also something deeply uncomforting about it. In relation to monumental time our lives are exposed as terribly little, terribly fleeting. I wonder if this terrible aspect of monumental time has come to the fore in our time? Do we turn our little fleeting lives away from the monumental precisely because we cannot stand to be exposed to any reminder of our own inexorable passing? Why, nine years later, is there no World Trade Center monument to the lives lost on 11 September 2001? Its absence is troubling.

Calenders, though, are reassuring objects. Usually. I have one on my office wall: coloured ink on shiny paper. An entire year manageably contained and sectioned into even more manageable semester-sized and month-sized bits. The entire year is mine to dwell within and wander through. The proof is on my wall. 
And because the calendar on my wall is specifically marked with the bold numbers 2009, I am also reassured that I will not be stuck within this year forever. Come January I'll be given a brand new year, 2010, manageably contained and sectioned into even more manageable bits. The calendar in my electronic organiser is also reassuring, if a bit daunting. When I turn it on a flashing number within a monthly calendar flashes me the present day. That we are so often in agreement is very reassuring. It's only daunting when I scroll into the future. The calendar is prepared to scroll all the way to 9999. I am not. It's too distant, too long away; it makes me woozy if I really think about it.

I didn't realise how reassuring most calendars are until I began to think about the Mayan calendar. More specifically, the Mayan 'long count' calendar-and the specificity matters, for the Mayans had three different calendar systems. It's only the 'long count' system that will reach its dramatic denouement on 21 December (or 23 December, there is some disagreement) of the year 2012 of the Common Era. Or of the year 2012 Anno Domini, depending on your calendrical preference. The Mayan calendar is bewilderingly beautiful. A circular stone tablet covered in hieroglyphs, apparently the 'long count' divides this time into thirteen sections, each with a further division into four hundred sections. All of it, over five thousand years, chiselled into one piece of stone. So much time, all in one place-a circular tablet. It reminds me of one of my wristwatches, in a way. It too is circular, and it divides time into twelve sections, each with a further division into five sections. Oddly enough I've never met anyone who was in a panic about the fact their watch was going to come to the end of its cycle. There are, however, numerous people exhibiting some degree of anxiety over the impending end of the Mayan long count calendar. There are books on the subject available for purchase from new age websites and bookstores. They imagine and tell either a cataclysmic end to human existence, or the flick of a solstice-switch transition into an era of cosmic relational harmonydeeply nice. Mesoamerican scholars note this is utter rubbish, that the long count will simply begin again and cycle through another five thousand plus years. Their books on the subject do not sell nearly as well as the doom \& boom or cosmic bliss variety. This may be because both doom $\&$ boom and cosmic bliss are the very stuff of myth, of 'In the beginning the Gods [followed by a great many improbable, exciting events]. Thus it came to pass [exciting list of more improbable events]. And 
at the End [bloody mess for a great many and/or some sort of blissful perfection and/or a clean and shiny new beginning for some].'

The temporality materialised through myth was perhaps the first temporality to be humanly imagined that wasn't directly related to the rising and setting of the sun, or to the changing of the seasons, or to the fact of individual human birth and aging and death-although it usually does address all those things. More broadly, more amazingly, mythical time is a collective temporality, a temporality that collects and holds an entire people in its embrace. The temporality of myth also provides a people with an unwavering temporal compass. Its needle points always in two directions simultaneously. 'Then' and 'then', marks myth. And suddenly all that time in the middle, the improbable, bewildering 'now', becomes meaningful-meaningful for an entire people in relation to that people's two distant 'thens'.

However, it seems that 'then', both 'thens', must be set at a sufficient distance from each other and from 'now' in order for 'now's' meaningfulness to maintain its fullness. I think that whenever a 'then' is deemed to be rapidly approaching, to be in too intimate a relation with 'now' - at those times 'now' seems to leak like a sieve, its meaning displaced, emptied out by the approach of an immensely more meaningful 'then'. But of course after a time 'then' retreats, the necessary distance is re-established, and 'now' refills with a modicum of meaning. Myths are wise time tellers. They know that 'then' must never be allowed to become 'now'. But calendars are wise, too. Calendars know we need reassuring. Here and now, today, we seem to need the reassuring promise that tomorrow will come, and next month, and next year will also be ours. It's only when calendars count too far ahead or appear to come to a halt that they get daunting, and I suspect this is because at that point they are encroaching upon the ends of mythical time-those distant temporal spaces which are never meant to be lived, but which are required if lived time is to be collectively meaningful now.

What time is it now? Whenever I ask my students what time it is they dutifully look at their watches and I get a lovely variety of answers. Still, in relation to that range I am able to get a sense of when it's about time to begin the lecture. From these non- 
scientific surveys I've also gained the sense that watches, while definitely material objects that on the face of it tell the time, don't tell time at all. Instead, watches tell us daily doings. Oh look, time to get up, time to go to work, time to go to that meeting, time to have a cup of tea, time to prepare that lecture, time to take the car to the shop, time to pick up the kids, and so on. Watches, I think, are amulets that protect us, that ward off temporal daze and temporal drift. That is, they seem to function as handrails, supporting us as we stumble through our daily routine. Watches tell us to do stuff. They do not tell us simply to be. (Ritual time may tell us when to be, and it might be the case that the more time one dwells within ritual time the better one learns how simply to be, but watches tell us to do. Look, it's time for another coffee...) Like calendars, in a way, watches reassure us. But, also like calendars, they do not answer the question with which I began. When are we now?

I am buggered if I know how to tell. Yesterday, when engaged in my weekly hunt for groceries, I was attacked by plastic Santas. I checked this morning, and the calendar still said October. Cyclical time seems to have gone awry, at least in its human materialisations. Neither Santa's reindeer nor the Easter Bunny can be trusted to appear or disappear in a timely fashion. It is as though the sudden absence of temporal progress has unleashed a score of other temporal configurations. They mill about, dazed critters, jostling us along.

If each era is both burdened and held loosely together by one temporal modality that figures most strongly in the cultural imagination, then what happens when that temporality collapses?

Lucy Tatman is the coordinator of the Gender Studies Program and Head of School of Philosophy at the University of Tasmania. 
-NOTES

${ }^{1}$ Julia Kristeva, Proust and the Sense of Time, trans. Stephen Bann, Columbia University Press, New York, 1993, p. 4.

2 On the difference between information and knowledge, see for example Mary Midgley, Wisdom, Information and Wonder: What is Knowledge For?, Routledge, London, New York, 1989, pp. 6-11. 3 For an insightful discussion of 'the end of a number of grammatical tenses', see Jean-Claude Carrière, 'Answering the Sphinx', in Umberto Eco, Stephen Jay Gould, Jean-Claude Carrière and Jean Delumeau, Conversations about the End of Time, trans. Ian Maclean and Roger Pearson, Penguin, London, 1999, pp. 97-9.

${ }^{4}$ With a wink and a nod to Martin Heidegger.

5 Julia Kristeva, 'Women's Time', trans. Ross Guberman, in New Maladies of the Soul, Columbia University Press, New York, 1995, pp. 204-5. I should note, however, that throughout my reading of 'Women's Time' I move between both English translations of the essay: Julia Kristeva, 'Women's Time', trans. Alice Jardine and Harry Blake, in Nannerl O. Keohane, Michelle Z. Rosaldo and Barbara C. Gelpi (eds), Feminist Theory: A Critique of Ideology, The University of Chicago Press, Chicago, 1982, and Julia Kristeva, 'Women's Time', trans. Ross Guberman, in New Maladies of the Soul, New York: Columbia University Press, New York, 1995.

6 This dismal picture is laid out most succinctly in a report commissioned by the Pentagon. See Peter Schwartz and Doug Randall, 'An Abrupt Climate Change Scenario and Its Implications for United States National Security', October 2003,

<http://www.environmentaldefense.org/documents/3566_AbruptClimateChange.pdf>.

${ }^{7}$ Adrienne Rich, An Atlas of The Difficult World, W.W. Norton \& Co, New York, London, 1991, p. 4.

8 Fredric Jameson, 'The End of Temporality', Critical Inquiry, vol. 29, no. 4, 2003, p. 713.

9 Jameson, p. 709.

10 Jameson, pp. 710-12.

11 Donna Haraway, 'Ecce Homo: Ain't (Ar'n't) I a Woman, and Inappropriate/D Others', in Judith Butler and Joan Scott (eds), Feminists Theorize the Political, Routledge, New York, London, 1992, p. 86.

12 Rosi Braidotti, Nomadic Subjects: Embodiment and Sexual Difference in Contemporary Feminist Theory, Cloumbia University Press, New York, 1994, pp. 3-4.

13 Bart Verschaffel, 'The Monumental: On the Meaning of a Form', The Journal of Architecture, vol. 4, no. 4, 1999, p. 333.

${ }^{14}$ Huston Smith, The World's Religions, HarperCollins, San Francisco, 1991, p. 68.

15 Verschaffel, p. 335.

16 Julia Kristeva, 'Women's Time', 1982, p. 34. 